\title{
Light interception and utilization of four grain legumes sown at different plant populations and depths
}

\author{
S. AYAZ, B. A. McKENZIE, D. L. McNEIL* AND G. D. HILL† \\ Plant Sciences Group, Soil, Plant and Ecological Sciences Division, P.O. Box 84, Lincoln University, \\ Canterbury, New Zealand \\ (Revised MS received 24 May 2004)
}

\begin{abstract}
SUMMARY
Canopy development, radiation absorption and its utilization for yield was studied in four grain legume species Cicer arietinum, Lens culinaris, Lupinus angustifolius and Pisum sativum. The grain legumes were grown at different plant populations and sowing depths over two seasons in Canterbury, New Zealand. The green area index (GAI), intercepted radiation, radiation use efficiency (RUE) and total intercepted photosynthetically active radiation (PAR) increased significantly $(P<0 \cdot 001)$ with increased plant population. Narrow-leafed lupin produced the highest maximum biomass $(878$ and $972 \mathrm{~g} / \mathrm{m}^{2}$, averaged over all populations during 1998/99 and 1999/2000, respectively) and intercepted more radiation (600 and $714 \mathrm{MJ} / \mathrm{m}^{2}$, averaged over all populations during 1998/99 and 1999/2000, respectively) than the other three legumes. In all four species, in both trials, the highest plant populations reached their peak GAI about 7-10 days earlier than legumes sown at low populations. Cumulative intercepted PAR was strongly associated with seed yield and crop harvest index (CHI).

The RUE increased (from 1.10 to 1.46 and from 1.04 to 1.34 g/MJ during 1998/99 and 1999/2000, respectively) as plant population increased and was highest in the highest yielding species (e.g. 146 and $1.36 \mathrm{~g} / \mathrm{MJ}$ for narrow-leafed lupin in both experiments). The larger leaf canopies produced at the higher plant populations reduced the extinction coefficient $(k)$.

The results suggest that in the subhumid temperate environment of Canterbury, grain legume species should be selected for the development of a large GAI. This should maximize PAR interception, DM production and, consequently, seed yield.
\end{abstract}

\section{INTRODUCTION}

In Canterbury, grain legumes have the potential to produce high seed yields but yield varies from species to species, and from season to season. In grain legumes differences in total dry matter (TDM) production were due to differences in both their light utilization efficiency and the amount of light intercepted (Pilbeam et al. 1991). Total dry matter production in lentil (Lens culinaris) (McKenzie \& Hill 1991) and seed yield in faba bean (Vicia faba) (Husain et al. 1988) were both directly related to intercepted solar radiation.

The green area index (GAI) and leaf angle of a crop determines the amount of radiation absorption,

\footnotetext{
* Present address: DNRE, Victorian Institute for Dryland Agriculture, PMB 260, Horsham, Victoria 3401, Australia.

$\dagger$ To whom all correspondence should be addressed. Email: hill1@lincoln.ac.nz
}

which is decisive in determining TDM production (Ashraf et al. 1994). A large GAI is required to fully intercept incident solar radiation (Thomson \& Siddique 1997). In several crops seed yield is closely related to TDM production (Loss et al. 1998a). For many crops this is proportional to the amount of intercepted radiation (Thomson \& Siddique 1997). Therefore, high TDM production is associated with a high GAI (Ashraf et al. 1994). Greater GA development, radiation absorption and TDM production have been reported in faba bean sown at high plant populations in both temperate and in Mediterranean environments by Stützel \& Aufhammer (1992) and in lentil in Canterbury (McKenzie \& Hill 1991).

The fraction of light interception $\left(F_{\mathrm{i}}\right)$ by a crop is a function of its GAI and the extinction coefficient $(k)$. This is governed by a number of factors such as plant species, leaf size, leaf shape, elevation of the sun and the proportion of direct and diffused solar radiation (Hay \& Walker 1989; Thomson \& Siddique 1997). 
Table 1. MAF soil quick test for 0-30 cm depth for the Horticultural Research area (1998/99) and the Henley Research farm (1999/2000) of Lincoln University, Canterbury. $\mathrm{Ca}, \mathrm{K}, \mathrm{P}, \mathrm{Mg}, \mathrm{Na}$ and $\mathrm{S}$ and $\mathrm{NH}_{4}^{+}, \mathrm{NO}_{3}^{-}$are expressed as $\mu \mathrm{g} / \mathrm{g}$ soil, and total $N(T N)$ and $C$ as $\mathrm{mg} / \mathrm{g}$ soil

\begin{tabular}{lrrrrrrrrrrr}
\hline \hline Season & $\mathrm{pH}$ & $\mathrm{Ca}$ & $\mathrm{K}$ & $\mathrm{P}$ & $\mathrm{Mg}$ & $\mathrm{Na}$ & $\mathrm{S}$ & $\mathrm{C}$ & $\mathrm{NH}_{4}^{+}$ & $\mathrm{NO}_{3}^{-}$ & $\mathrm{TN}$ \\
\hline $1998 / 1999$ & $5 \cdot 4$ & 7 & 8 & 27 & 16 & 5 & 9 & 24 & - & 1 & $2 \cdot 0$ \\
$1999 / 2000$ & $5 \cdot 8$ & 10 & 9 & 12 & 28 & 8 & 9 & - & 5 & $<1$ & $2 \cdot 7$ \\
\hline \hline
\end{tabular}

In Canterbury, reported $k$ values for field bean (Vicia faba) are 0.36-0.48 (Husain et al. 1988). McKenzie \& Hill (1991) found a $k$ value of $0 \cdot 26$ for lentil. However, there is no published data for the $k$ value of narrow-leafed lupin (Lupinus angustifolius) or desi chickpea (Cicer arietinum) in a subhumid temperate environment like Canterbury. Thomson $\&$ Siddique (1997) reported $k$ values of 1.06 for pea and 0.91 among the lupin species Lupinus albus, $L$. angustifolius, L. atlanticus and L. pilosus and 0.76 for lentil. Thomas \& Fukai (1995) reported a value of 1.10 in chickpea, in Australia, and there was a range of 0.47-0.61 in Syria (Hughes et al. 1987).

Different grain legumes have different leaf sizes, growth patterns and photosynthetic functions. This provides a range of differences in their radiation use efficiency (RUE; the ratio of TDM to total intercepted photosynthetically active radiation (PAR)). It also gives different GAIs at which radiant energy interception approaches a maximum (Hipps et al. 1983).

The RUE is a key determinant of crop yield. In Canterbury it ranges from $2 \cdot 0-2 \cdot 5 \mathrm{~g} / \mathrm{MJ}$ in pea (Pisum sativum) (Zain et al. 1983), and 1.6-1.8 g/MJ in lentil (McKenzie \& Hill 1991). In other environments, the highest RUE values reported in grain legumes were $1 \cdot 15-1 \cdot 26 \mathrm{~g} / \mathrm{MJ}$ for soybean (Glycine max), and in pea it ranged from $0 \cdot 98-1 \cdot 12 \mathrm{~g} / \mathrm{MJ}$ (Sinclair \& Muchow 1999). Faba bean had a highly variable RUE, which ranged from $1.03 \mathrm{~g} / \mathrm{MJ}$ (Silim \& Saxena 1992) to $2.04 \mathrm{~g} / \mathrm{MJ}$ (Fasheun \& Dennett 1982).

Lentils and desi chickpeas have much smaller leaflets (Singh 1997) than narrow-leafed lupin and pea, and it is of interest to know their basic response to solar radiation. Birch et al. (1998) reported that more, and larger, leaves in maize (Zea mays) had a higher PAR interception which consequently gave a higher TDM production. Similar results have been reported in rice (Oryza sativa) (Ashraf et al. 1994).

There is limited information on grain legumes, which compares their canopy development, canopy geometry and RUE when sown at different plant populations and depths in subhumid temperate environment such as Canterbury. The present study was designed to investigate the effects in four grain legumes sown at different plant populations and depths on (1) radiation interception, DM production and the relationship between them; and (2) the extinction coefficient and its relationship with RUE, in an attempt to explain variations in RUE through differences in canopy structure.

\section{MATERIALS AND METHODS}

Details of the experimental design, crop species, crop husbandry, standard measurements and procedures are described in Ayaz et al. (2004).

Briefly, in 1998/99, the design used was a split plot with four grain legumes (desi chickpea, Cicer arietinum; lentil, Lens culinaris cv. Rajah; narrowleafed lupin, Lupinus angustifolius cv. fest; and field pea Pisum sativum cv. Beacon) as main plots. Subplots were four plant populations: $0 \cdot 1 \times$ optimum, $1 \cdot 0 \times$ optimum, $2 \cdot 0 \times$ optimum and $4.0 \times$ optimum. Optimum populations were 50 plants $/ \mathrm{m}^{2}$ for chickpea, 150 plants $/ \mathrm{m}^{2}$ for lentil and 100 plants $/ \mathrm{m}^{2}$ for both lupin and pea.

The experiment was located at the Horticultural Research Area in 1998/99 and at the Henley Research Farm in 1999/2000, of Lincoln University, Canterbury, New Zealand $\left(43^{\circ} 38^{\prime} \mathrm{S}, 172^{\circ} 30^{\prime} \mathrm{E}\right)$.

In 1999/2000, the experiment was a split-split plot design with the same four legumes as main plots. The subplots were three plant populations $(10,100$ and 400 plants $\left./ \mathrm{m}^{2}\right)$ and three sowing depths $(2,5$ and $10 \mathrm{~cm}$ ) were sub-subplots. Experiment 1 was given $75 \mathrm{~mm}$ of water by sprinkler irrigation. No irrigation was applied to Expt 2. Both sites were a Wakanui silt loam soil (Hewitt 1992). A Ministry of Agriculture and Fisheries (MAF) soil quick test was done each season to determine available soil nutrients (Table 1).

Details of the climate in both seasons are given in Fig. 1. The data were from the Broadfields Meterological station located at about $1 \mathrm{~km}$ from both trial sites.

\section{Measurements}

The green area index (GAI) and the amount of radiation transmitted through the canopy $\left(T_{\mathrm{i}}\right)$ were measured in both experiments using a LICOR LAI 2000 Plant Canopy Analyser (LICOR Inc., Lincoln, Nebraska, USA). The GAI and $T_{\mathrm{i}}$ were measured weekly from 35 days after sowing (DAS) until 


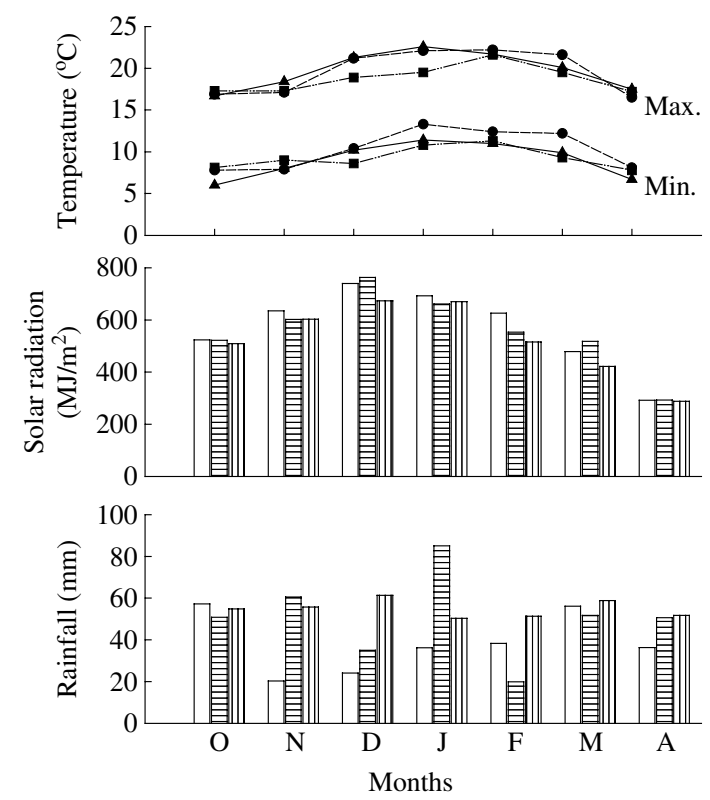

Fig. 1. Climate data for the $1998 / 99$ ( $\square$, O) and 1999/2000 $(\mathrm{E}, \boldsymbol{\bullet})$ growing seasons and long-term means $(\mathbb{\square}, \mathbf{\Delta})$ for Lincoln University, Canterbury, New Zealand. (Long-term means for rainfall and temperature 1944-99; solar radiation 1975-99.)

physiological maturity of each species in 1998/1999 and at 10-12 days' interval from 31 DAS until physiological maturity in 1999/2000. Four above and below canopy measurements were taken per plot per session. The proportion of radiation intercepted $\left(F_{\mathrm{i}}\right)$ by the canopy was calculated using the technique of Gallagher \& Biscoe (1978).

$$
F_{\mathrm{i}}=1-T_{\mathrm{i}}
$$

The amount of photosynthetically active radiation (PAR) absorbed by the crop $\left(S_{\mathrm{a}}\right)$ was calculated from (Szeicz 1974):

$$
S_{\mathrm{a}}=F_{\mathrm{i}} \times S_{\mathrm{i}}
$$

where $S_{\mathrm{i}}$ is the total incident PAR.

The extinction co-efficient $(k)$ of the canopy was calculated from the slope of the regression line between $\ln \left(1-F_{\mathrm{i}}\right)$ and GAI (Monteith 1965).

$$
k=-\ln \left(1-F_{\mathrm{i}}\right)
$$

\section{Statistical analysis}

All variates were analysed using analysis of variance. The statistical package used was Genstat. Standard errors (s.E.), coefficient of variation (CV as a \%) and percentage variation accounted for, the correlation coefficient $(r)$, were also calculated.

\section{RESULTS}

\section{Climate}

The weather from October 1998 to April 1999 was dry and rainfall was about $40 \%$ less than the long-term average (Fig. 1). Mean temperature and solar radiation were higher than the long-term average by 5 and $7 \%$, respectively, from January to March 1999. In the second year, rainfall was about $90 \%$ of the long-term average $(385 \mathrm{~mm})$. The mean monthly maximum temperatures during December 1999 and January 2000 were lower, at 18.9 and $19.5{ }^{\circ} \mathrm{C}$, than the long-term averages values of 21.3 and $22.6{ }^{\circ} \mathrm{C}$ respectively (Fig. 1). Solar radiation from December 1999 to March 2000 was about $10 \%$ higher than the longterm mean.

\section{Green area index}

There was a significant trend for GAI to increase at higher plant populations from about 45 DAS until close to physiological maturity in both seasons. In $1998 / 99$, the plant population of $0 \cdot 1 \times$ optimum reached a peak GAI of 2.38 in chickpea, 2.63 in lentil, 3.72 in narrow-leafed lupin and 3.58 in field pea, compared with $4 \cdot 20,4 \cdot 33,6 \cdot 10$ and 5.62 at $4.0 \times$ optimum population, respectively (Fig. $2 a-d$ ). In $1999 / 2000$, the highest populations achieved their maximum GAI about 10 days earlier than the lowest population (Fig. $2 e-h$ ). The maximum GAIs at 400 plants $/ \mathrm{m}^{2}$ in chickpea, lentil, narrow-leafed lupin and field pea were $4 \cdot 73,4 \cdot 56,6.00$ and 5.83 , respectively.

In both seasons, GAI declined rapidly at the higher populations after peak GAI was achieved. However, it remained constant or increased at $0 \cdot 1 \times$ optimum population in the first year and at 10 plants $/ \mathrm{m}^{2}$ in the second year. All four legumes showed similar trends. As crops senesced, GAI decreased.

\section{Radiation interception}

In 1998/99, field pea intercepted $95 \%$ of incident solar radiation by 56 DAS. Comparable values were $75 \%$ for lentil, $70 \%$ for narrow-leafed lupin and $58 \%$ for chickpea (Fig. $3 a-d$ ). Similarly in 1999/2000, field pea intercepted $90 \%$ of the incident radiation by 62 DAS, while lentil, narrow-leafed lupin and chickpea intercepted 70,78 and $80 \%$, respectively, by the same time (Fig. $3 e-h$ ). Similar trends to those in GAI were evident in the proportion of intercepted radiation $\left(F_{\mathrm{i}}\right)$.

Significantly $(P<0 \cdot 001)$ more radiation was intercepted at the highest plant population in both seasons (Fig. 3). The maximum $F_{\mathrm{i}}$ was about $95 \%$ in both seasons and generally it coincided with peak GAI. The $F_{\mathrm{i}}$ did not decline as rapidly as the GAI. However, radiation interception generally followed similar patterns in all species and $F_{\mathrm{i}}$ was strongly affected by 

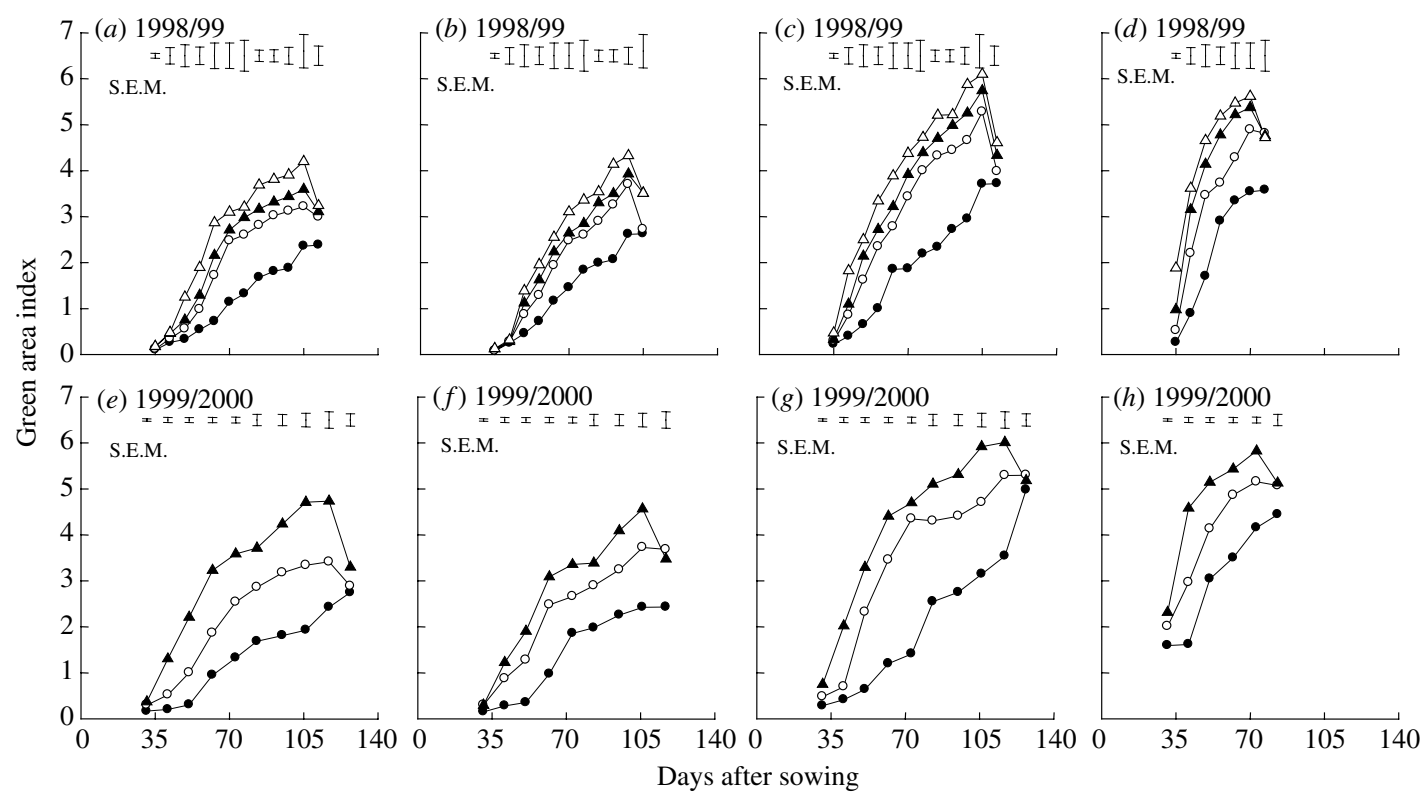

Fig. 2. The Green area index over the growing seasons of four grain legumes sown at different plant populations, (i) 1998/1999 $(a-d): 0 \cdot 1 \times$ optimum $(\bullet), \quad 1 \cdot 0 \times$ optimum $(\bigcirc), \quad 2 \cdot 0 \times$ optimum $(\mathbf{\Delta}), \quad 4 \cdot 0 \times$ optimum $(\triangle)$, (ii) $1999 /$ $2000(\mathrm{e}-\mathrm{h}): 10$ plants $/ \mathrm{m}^{2}(\bullet), 100$ plants $/ \mathrm{m}^{2}(\bigcirc), 400$ plants $/ \mathrm{m}^{2}(\boldsymbol{\Delta}) .(a, e)$ chickpea, $(b, f)$ lentil, $(c, g)$ narrow-leafed lupin, $(d, h)$ pea.
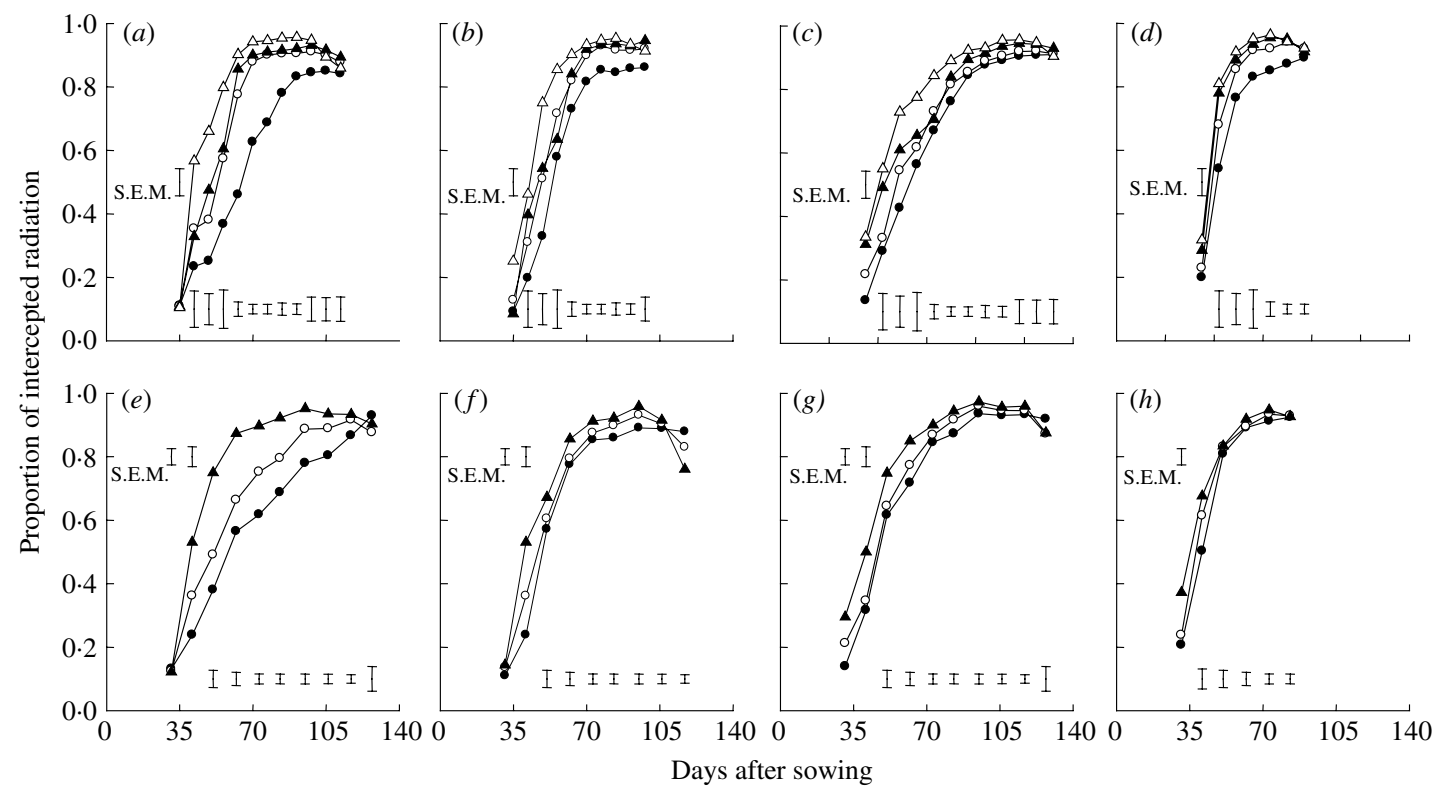

Fig. 3. The proportion of intercepted radiation $\left(F_{\mathrm{i}}\right)$ up to maximum green area index over two growing seasons of four grain legumes sown at different plant populations, (i) 1998/1999 $(a-d): 0 \cdot 1 \times$ optimum $(\mathbf{O}), 1 \cdot 0 \times$ optimum $(\bigcirc), 2 \cdot 0 \times$ optimum $(\mathbf{\Delta})$, 4.0 $\times$ optimum $(\triangle)$, (ii) $1999 / 2000(e-h): 10$ plants $/ \mathrm{m}^{2}(\bullet), 100$ plants $/ \mathrm{m}^{2}(\bigcirc), 400$ plants $/ \mathrm{m}^{2}(\boldsymbol{\Delta})$. $(a, e)$ chickpea, $(b, f)$ lentil, $(c, g)$ narrow-leafed lupin, $(d, h)$ pea. 

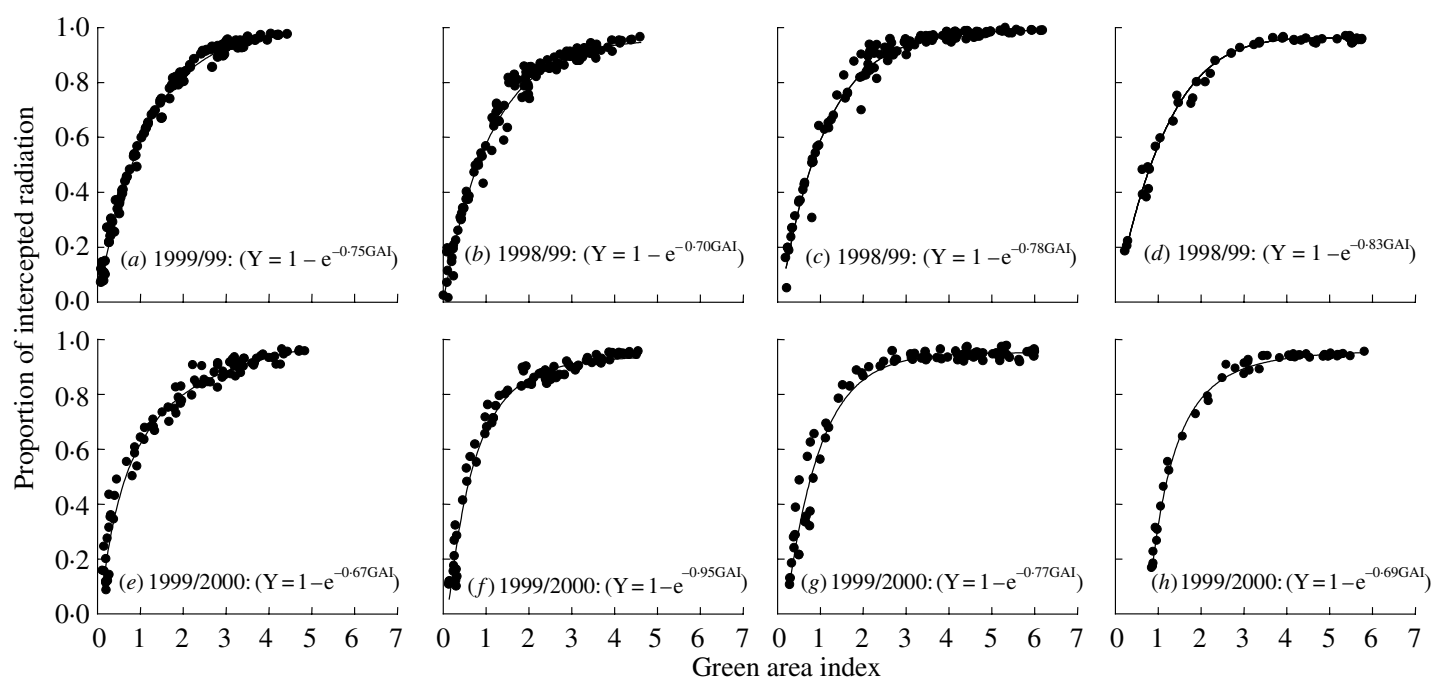

Fig. 4. The relationship between green area index and the proportion of intercepted radiation in four grain legumes sown at different plant populations, 1998/1999 and 1999/2000. $(a, e)$ chickpea, $(b, f)$ lentil, $(c, g)$ narrow-leafed lupin, $(d, h)$ pea.

GAI, which showed a typical exponential function (Fig. 4). A GAI of 3.5-4.0 was required to intercept $90-95 \%$ of incident radiation in chickpea. To intercept the same amount of incident radiation in lentil, narrow-leafed lupin and field pea required GAIs of $4 \cdot 2-4 \cdot 5,3 \cdot 1-3 \cdot 5$ and $3 \cdot 1-3 \cdot 8$, respectively.

\section{Total intercepted PAR}

In both seasons total intercepted photosynthetically active radiation (PAR) varied significantly among species $(P<0 \cdot 001)$ and populations $(P<0 \cdot 001)$. However, their interactions were also significant $(P<0 \cdot 05)$. In 1998/99, narrow-leafed lupin intercepted the most PAR at $600 \mathrm{MJ} / \mathrm{m}^{2}$. Lowest interception of $366 \mathrm{MJ} / \mathrm{m}^{2}$ was in pea (Table 2). The species by population interaction (Table 3) $(P<0.05)$ shows that chickpea, lentil and field pea responded in the same way to increased plant population by intercepting about $50 \%$ more intercepted PAR. However, there was only a $25 \%$ increase in intercepted PAR when plant population increased from $0 \cdot 1 \times$ optimum to $4 \cdot 0 \times$ optimum in narrow-leafed lupin. In 1999/2000, narrow-leafed lupin had a $60 \%$ higher total intercepted PAR than pea (Table 2). In all four species higher populations intercepted more PAR than the lower populations (Table 4).

In 1999/2000, different sowing depths also gave significant differences $(P<0 \cdot 05)$ in light interception. However, intercepted PAR was only increased by $5 \%$ as sowing depth increased from 2 to $10 \mathrm{~cm}$. On average, in 1999/2000 all four species intercepted $25 \%$ more PAR than in 1998/99 (Table 2).

\section{The extinction coefficient}

The extinction coefficient $(k)$ of field pea $(k=0.83)$ was higher than that of the other three species in 1998/99. The $k$ of lentil $(0 \cdot 69)$ was lowest in this season (Fig. $5 a-d$ ). In 1999/2000, the $k$ of narrowleafed lupin was higher $(k=0.76)$ than in the other three species (Fig. $5 e-h$ ). Averaged over both seasons, the $k$ of chickpea, lentil, narrow-leafed lupin and field pea was $0 \cdot 70,0 \cdot 67,0 \cdot 77$ and 0.76 , respectively. The value of $k$, among the different plant populations, decreased slightly with increased plant population. Therefore only pooled data for all populations in each year are shown.

\section{Radiation use efficiency}

In 1998/99 radiation use efficiency (RUE) varied significantly among legume species $(P<0 \cdot 001)$ and populations $(P<0 \cdot 001)$ (Fig. 6). The RUE tended to increase with DAS to a maximum level in each species at each population density and then the RUE declined to that of the lowest population. Field pea at $4.0 \times$ and $2.0 \times$ optimum population had the highest RUE of $1.68 \mathrm{~g} \mathrm{DM} / \mathrm{MJ}$ intercepted PAR, at 49 DAS. In narrow-leafed lupin, the highest RUE was $1.40 \mathrm{~g}$ $\mathrm{DM} / \mathrm{MJ}$ intercepted PAR at $4.0 \times$ optimum population at 63 DAS.

Species, population and their interactions all significantly affected the final RUE. In both seasons the RUE of lentil was lower than in the other three species (Table 2). In 1998/99, RUE tended to increase in all four species, as population increased up to 
Table 2. The effect of legume species, plant population and sowing depth on total seasonal intercepted photosynthetically active radiation $(P A R)$ and radiation use efficiency (RUE) in Canterbury in 1998/1999 and $1999 / 2000$

\begin{tabular}{|c|c|c|}
\hline Treatments & $\begin{array}{c}\text { Total PAR } \mathrm{PAR}_{\mathrm{i}} \\
\left(\mathrm{MJ} / \mathrm{m}^{2}\right)\end{array}$ & $\begin{array}{c}\text { RUE } \\
(\mathrm{g} / \mathrm{MJ})\end{array}$ \\
\hline \multicolumn{3}{|l|}{ 1998/99 } \\
\hline \multicolumn{3}{|l|}{ Species (S) } \\
\hline Chickpea & 489 & $1 \cdot 25$ \\
\hline Lentil & 368 & $1 \cdot 11$ \\
\hline Lupin & 600 & $1 \cdot 46$ \\
\hline Pea & 366 & 1.42 \\
\hline S.E. (D.F. = 3) & $4 \cdot 73$ & $0 \cdot 017$ \\
\hline \multicolumn{3}{|l|}{ Population (P) } \\
\hline $0 \cdot 1 \times$ optimum & 364 & $1 \cdot 10$ \\
\hline $1.0 \times$ optimum & 454 & 1.42 \\
\hline $2.0 \times$ optimum & 479 & 1.46 \\
\hline $4.0 \times$ optimum & 527 & $1 \cdot 31$ \\
\hline S.E. (D.F. $=3$ ) & $5 \cdot 64$ & $0 \cdot 028$ \\
\hline CV \% & $4 \cdot 3$ & $7 \cdot 2$ \\
\hline \multicolumn{3}{|l|}{$1999 / 2000$} \\
\hline \multicolumn{3}{|l|}{ Species (S) } \\
\hline Chickpea & 634 & 1.24 \\
\hline Lentil & 522 & 0.90 \\
\hline Lupin & 714 & $1 \cdot 36$ \\
\hline Pea & 447 & $1 \cdot 32$ \\
\hline S.E. (D.F. = 3) & $9 \cdot 59$ & $0 \cdot 021$ \\
\hline \multicolumn{3}{|l|}{ Population (P) } \\
\hline 10 plants $/ \mathrm{m}^{2}$ & 466 & 1.04 \\
\hline 100 plants $/ \mathrm{m}^{2}$ & 594 & 1.25 \\
\hline 400 plants $/ \mathrm{m}^{2}$ & 678 & $1 \cdot 34$ \\
\hline S.E. $($ D.F. $=2)$ & $6 \cdot 58$ & $0 \cdot 017$ \\
\hline \multicolumn{3}{|l|}{ Depth (D) } \\
\hline $2 \mathrm{~cm}$ & 565 & $1 \cdot 23$ \\
\hline $5 \mathrm{~cm}$ & 581 & $1 \cdot 22$ \\
\hline $10 \mathrm{~cm}$ & 588 & 1.22 \\
\hline S.E. (D.F. =2) & $9 \cdot 25$ & 0.010 \\
\hline $\mathrm{CV} \%$ & $5 \cdot 3$ & $5 \cdot 8$ \\
\hline
\end{tabular}

$2 \cdot 0 \times$ optimum population (Table 3). In 1999/2000 their interaction (Table 4) showed that RUE was directly related to plant population from 10 to 400 plants $/ \mathrm{m}^{2}$. Averaged over all, the RUE was about $15 \%$ higher in 1998/99 than in 1999/2000 (Table 2). In both seasons $k$ was inversely related to RUE (Fig. 7).

\section{Correlations}

The relationship between total intercepted PAR and TDM production at final harvest in all four species in both years was linear (Fig. $8 a, b$ ). In both seasons, the regression accounted for about $90 \%$ of the variance and the slopes indicated RUE values of $1 \cdot 5,2 \cdot 0,1 \cdot 5$ and $2 \cdot 0 \mathrm{~g} \mathrm{DM} / \mathrm{MJ}$ of intercepted PAR for chickpea, lentil, narrow-leafed lupin and field pea, respectively. In 1998/99, seed yield was linearly correlated with total intercepted PAR (Fig. $8 c)\left(R^{2}>0 \cdot 77\right)(P<0 \cdot 01)$. Averaged over all four species, the relationship showed that $1.21 \mathrm{~g}$ of seed was produced per MJ of intercepted PAR. In 1999/2000, seed yield was again highly correlated with total intercepted PAR, and the regression accounted for $88 \%$ of the variance. The slope indicated $1.23 \mathrm{~g}$ of seed was produced per MJ of intercepted PAR (Fig. $8 d$ ). There were also strong associations $(P<0 \cdot 01)$ between intercepted PAR and CHI (Fig. $8 e, f$ ). In 1998/99 the $R^{2}$ values accounted for $>80 \%$ of the variance in all species, except in chickpea $\left(R^{2}=63 \%\right)$.

\section{DISCUSSION}

The quantity of solar radiation available to a plant determines its potential TDM production within the constraints imposed by other limiting factors such as water supply and nutrient availability. The quantity of PAR intercepted by a crop can be increased by rapid attainment of complete ground cover and by increasing the amount of canopy cover at any time, up to a definable threshold. Either mechanism can account for greater TDM production at high plant populations. Conversely, lower plant populations yielded less TDM, had lower GAIs and intercepted less PAR. All four legume species showed the same trend of increased GAI, intercepted PAR and biomass production as plant population increased. At the same time $k$ values decreased as population increased.

Different legume species had the ability to intercept different amounts of PAR. In the present study the highest total seasonal intercepted PAR was by narrow-leafed lupin and the lowest was in lentil and field pea. This is consistent with work on lentil by McKenzie \& Hill (1991) and chickpea by Anwar (2001) in Canterbury. In other environments, high yielding genotypes of Lens culinaris (Silim et al. 1993) and Pisum sativum (Martín et al. 1994) intercepted more solar radiation than lower yielding genotypes.

Plant population substantially influenced the proportion of intercepted radiation $\left(F_{\mathrm{i}}\right)$, and this followed a consistent pattern to the GAIs (Figs 2 and 3) as reported in other legume species (Loss et al. $1998 a$; Anwar 2001). This is a major factor in high radiation interception, as a large vegetative plant frame increased PAR interception in peanut (Arachis hypogaea) (Gardner \& Auma 1989). Singh (1991) found that a decrease in chickpea GAI caused a corresponding reduction in $F_{\mathrm{i}}$ by the canopy and TDM production.

Generally, $F_{\mathrm{i}}$ has been related to crop GAI by an exponential function (Trapani et al. 1992). In the present study, the best fit of an exponential function between $F_{\mathrm{i}}$ and GAI (Fig. 4) showed that the amount of radiation intercepted (pooled data of all populations) 
Table 3. The species by population interaction of total seasonal intercepted PAR $\left(M J / m^{2}\right)$ and final RUE $(g / M J)$ in Canterbury, 1998/99

\begin{tabular}{|c|c|c|c|c|}
\hline \multirow[b]{2}{*}{ Species } & \multicolumn{4}{|c|}{ Plant population } \\
\hline & $0 \cdot 1 \times$ optimum & $1.0 \times$ optimum & $2.0 \times$ optimum & $4 \cdot 0 \times$ optimum \\
\hline \multicolumn{5}{|c|}{ Total intercepted PAR $\left(\mathrm{MJ} / \mathrm{m}^{2}\right)$} \\
\hline Chickpea & 366 & 503 & 515 & 572 \\
\hline Lentil & 290 & 362 & 373 & 445 \\
\hline Lupin & 531 & 583 & 621 & 664 \\
\hline Pea & 270 & 368 & 405 & 425 \\
\hline S.E. (D.F. =9) & \multicolumn{4}{|c|}{$10 \cdot 86$} \\
\hline \multicolumn{5}{|c|}{ Final RUE (g/MJ) } \\
\hline Chickpea & $1 \cdot 10$ & $1 \cdot 35$ & $1 \cdot 38$ & $1 \cdot 21$ \\
\hline Lentil & $0 \cdot 66$ & $1 \cdot 31$ & $1 \cdot 33$ & $1 \cdot 15$ \\
\hline Lupin & $1 \cdot 40$ & $1 \cdot 47$ & $1 \cdot 48$ & $1 \cdot 46$ \\
\hline Pea & $1 \cdot 10$ & $1 \cdot 53$ & $1 \cdot 65$ & $1 \cdot 41$ \\
\hline S.E. (D.F. =9) & \multicolumn{4}{|c|}{$0 \cdot 052$} \\
\hline
\end{tabular}

Table 4. The species by population interaction of total seasonal intercepted PAR $\left(M J / m^{2}\right)$ and final RUE $(g / M J)$ in Canterbury, $1999 / 2000$

\begin{tabular}{|c|c|c|c|}
\hline \multirow[b]{2}{*}{ Species } & \multicolumn{3}{|c|}{ Population } \\
\hline & 10 plants $/ \mathrm{m}^{2}$ & 100 plants $/ \mathrm{m}^{2}$ & 400 plants $/ \mathrm{m}^{2}$ \\
\hline \multicolumn{4}{|c|}{ Total intercepted PAR $\left(\mathrm{MJ} / \mathrm{m}^{2}\right)$} \\
\hline Chickpea & 482 & 641 & 779 \\
\hline Lentil & 412 & 543 & 610 \\
\hline Lupin & 620 & 727 & 796 \\
\hline Pea & 349 & 464 & 529 \\
\hline S.E. $($ D.F. $=6)$ & & $14 \cdot 40$ & \\
\hline \multicolumn{4}{|c|}{ Final RUE (g/MJ) } \\
\hline Chickpea & $1 \cdot 10$ & $1 \cdot 32$ & $1 \cdot 33$ \\
\hline Lentil & $0 \cdot 62$ & 0.96 & $1 \cdot 10$ \\
\hline Lupin & $1 \cdot 34$ & $1 \cdot 32$ & $1 \cdot 41$ \\
\hline Pea & $1 \cdot 10$ & $1 \cdot 38$ & $1 \cdot 47$ \\
\hline S.E. (D.F. $=6$ ) & & $0 \cdot 035$ & \\
\hline
\end{tabular}

increased exponentially up to about $90-95 \%$ with increased GAI. An exponential function describing the relationship between $F_{\mathrm{i}}$ and GAI, has been found in other grain legumes in Canterbury (McKenzie \& Hill 1991; Anwar 2001).

Compared with 1998/99, in 1999/2000 all four legumes covered the ground more slowly and there was lower PAR absorption during the growing season. Species differences in TDM depended more on growth duration. Narrow-leafed lupin and chickpea had a much higher duration than pea and lentil. Again, this would give greater intercepted radiation. However, they all had higher yields (see Ayaz et al. 1999, 2001). In 1998/99, the crops took less time to reach their maximum GAI (Fig. 2). This may have been due to the slightly higher mean temperature and moisture stress caused by low rainfall $(200 \mathrm{~mm})$.
In contrast, in 1999/2000 rainfall was well distributed $(350 \mathrm{~mm})$ and conditions were cooler early in the growing season. Haloi \& Baldev (1986) found a chickpea crop attained a GAI of 7.5 with prolonged soil moisture availability.

Plant population had a significant positive effect on GAI, which had a sigmoid response over time. In all four legume species, in both seasons, GAI tended to increase with increased plant population. The highest populations reached their maximum GAIs earlier than the low plant population. This was consistent with the results of Loss et al. (1998b) who reported early canopy closure of faba beans when they were sown at high densities. McKenzie \& Hill (1991), working with lentil, also considered that high plant population gave earlier canopy closure. This increased GAI, radiation absorption and DM accumulation (Ayaz et al. 1999). The GAIs at high plant densities fell earlier but they remained constant at the low plant population. This might have been due to internal competition and leaf senescence at the higher plant populations (Herbert 1977). As expected, leaf senescence increased with increased plant population (data not presented).

\section{Intercepted $P A R$ and yield}

In both years highest total intercepted PAR was in narrow-leafed lupin and the lowest was in lentil and field pea. This was due to the large lupin canopy, which led to increased PAR interception (Table 2). Different species have the ability to intercept different amounts of PAR and this is consistent with work on lentil (284-582 MJ/m², McKenzie \& Hill 1991) and chickpea (284-562 MJ $/ \mathrm{m}^{2}$, Verghis 1996) in Canterbury. In the present study, high population density gave significantly earlier canopy closure; a high GAI, more radiation absorption, greater TDM 
Green area index

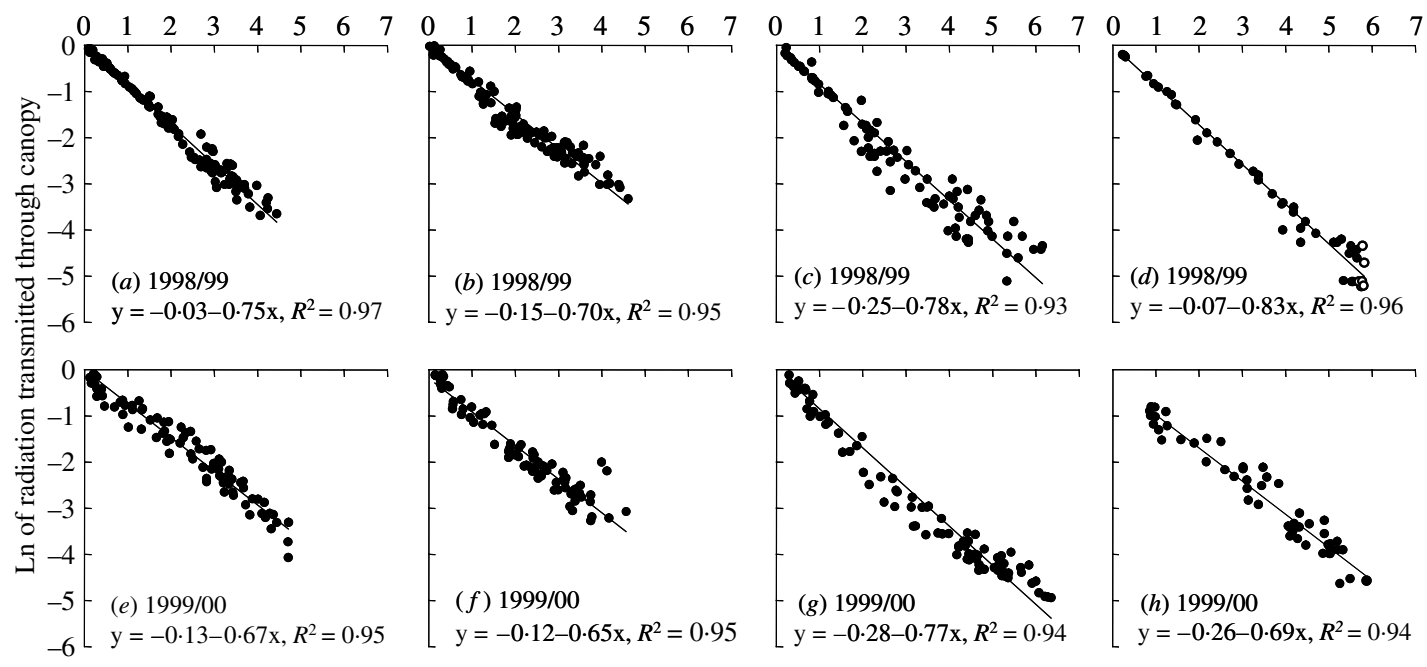

Fig. 5. The relationship between green area index and $I n$ of radiation transmitted through canopy of four grain legumes at different plant populations in 1998/99 and 1999/2000. $(a, e)$ chickpea, $(b, f)$ lentil, $(c, g)$ narrow-leafed lupin, $(d, h)$ pea.

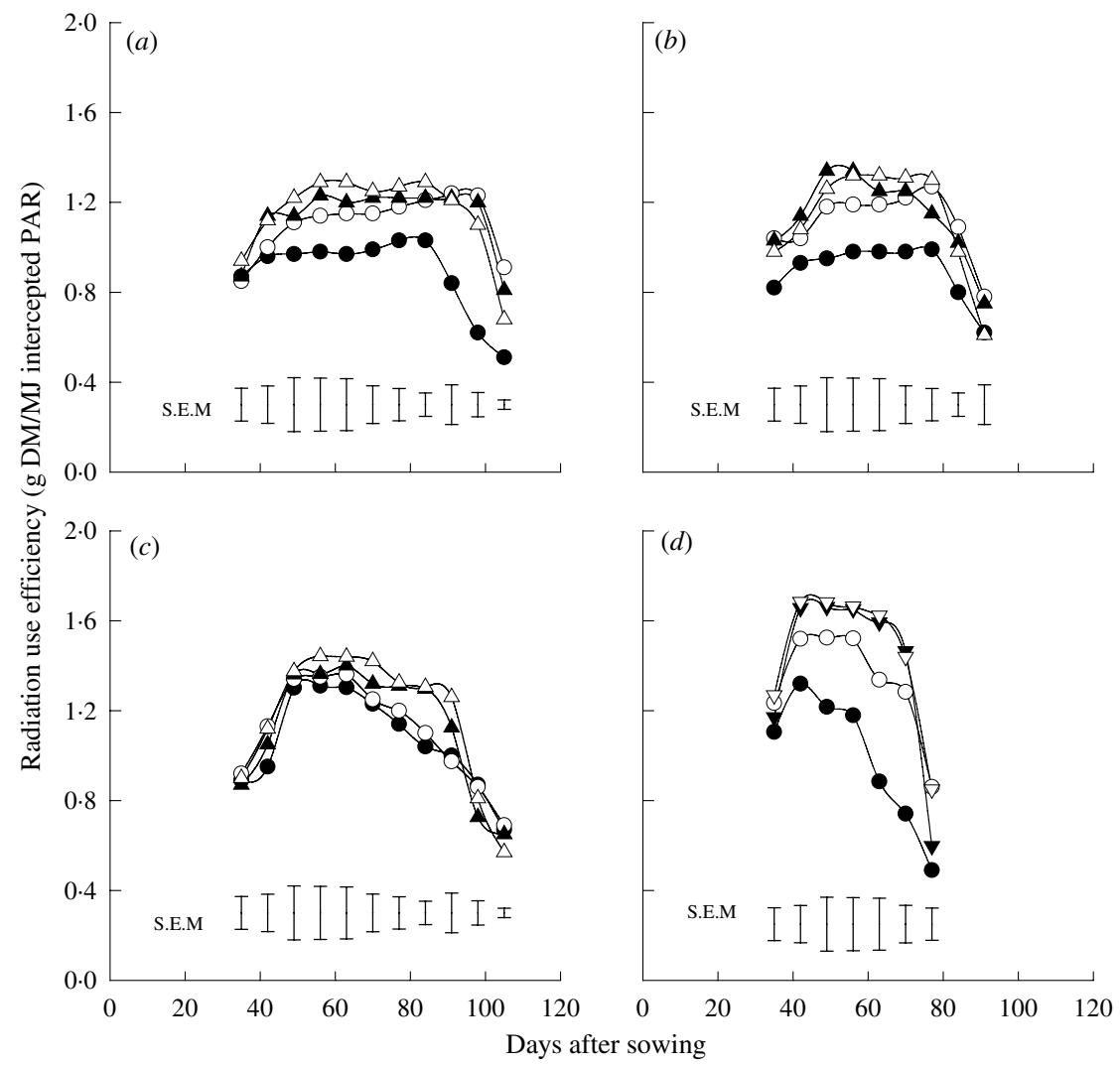

Fig. 6. The change in radiation use efficiency over the growing season in four plant populations of four grain legumes grown in Canterbury in 1998/99. (a) Chickpea, $(b)$ lentil, $(c)$ narrow-leafed lupin, $(d)$ pea. $0 \cdot 1 \times$ optimum $(\mathbf{O}), 1 \cdot 0 \times$ optimum $(\bigcirc)$, $2 \cdot 0 \times$ optimum $(\mathbf{\Delta}), 4 \cdot 0 \times$ optimum $(\triangle)$. 


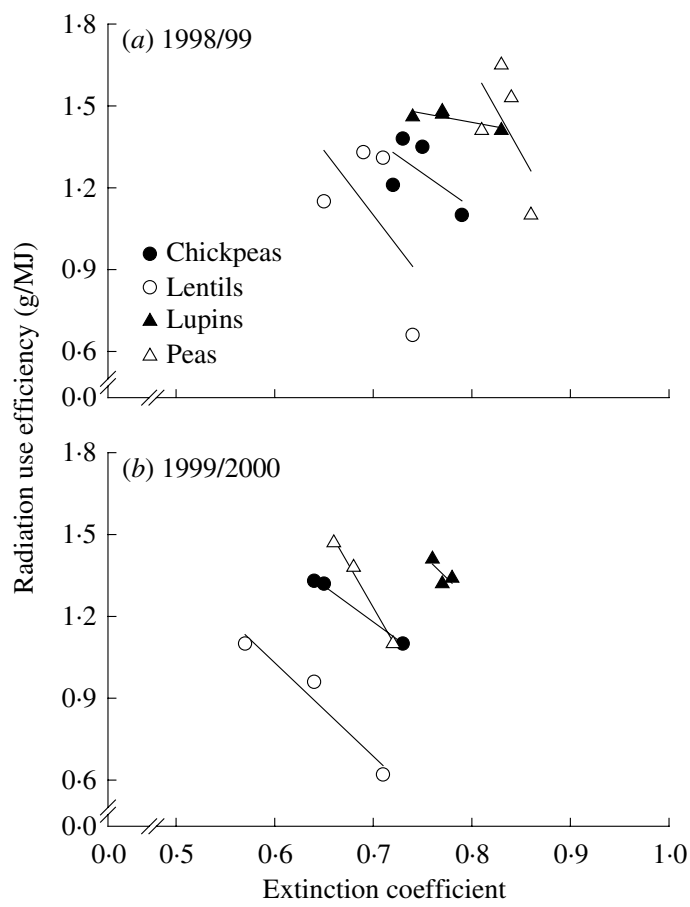

Fig. 7. The relationship between the extinction coefficient $(k)$ and radiation use efficiency (RUE) of four grain legumes sown at different plant populations in (a) 1998/99 and (b) $1999 / 2000$.

production and seed yield than the low population treatments. Increasing plant population from $0 \cdot 1 \times$ optimum to $4.0 \times$ optimum, increased intercepted PAR by about $45 \%$. There was a $30 \%$ increase in total intercepted PAR when lentil plant population increased from $1.0 \times$ optimum to $4.0 \times$ optimum (McKenzie \& Hill 1991).

In these experiments in $1999 / 2000$, GA development, radiation absorption, TDM production and crop harvest index (CHI) increased with increased plant population. However, in 1998/99, the CHI and yield of chickpea and field pea were relatively constant or declined at the highest plant population (Ayaz et al. 1999). This decline may have been due to pod dehiscence in the peas (Knott 1987), interplant competition or lower rainfall (Schulz et al. 1999).

In 1999/2000 sowing depth also affected total intercepted PAR. This may have been due to plants sown at the greatest depth having access to more available soil moisture (Wilson \& Thurling 1996). However, the difference, although significant, was small $(4 \%)$ and will not be discussed further.

Variation in crop yield can also be related to differences in radiation use efficiency (RUE) within species. Variations have been reported in RUE among four cereal species and in sunflower (Helianthus annuus) by
Kiniry et al. (1989) and among different genotypes of Vicia faba by Stützel \& Aufhammer (1992). This is strongly supported by data from the present study, where RUE varied among species. It was also influenced by plant population and by growing season. This suggests that the aim of crop modellers to use a universal value for each species to convert intercepted PAR into DM production is unrealistic. The final RUE value in 1998/99 was higher than in 1999/2000. As RUE is sensitive to minimum temperatures (Bell et al. 1993) the lower minimum temperatures in 1999/ 2000 might have contributed to the lower RUE values than in 1998/99 (Fig. 1). However, the highest yielding species had the highest RUE and these were closely related to the $\mathrm{CHI}$ for each species during each year of the present study. Stützel \& Aufhammer (1992), working with Vicia faba, reported that RUE cannot be expected to remain constant throughout the life cycle of a crop, during which growing conditions and the intensities of physiological processes may change. This is especially so late in the growing season when crop biomass is high and maintenance respiration demand will high.

There is no published information on the relationship between RUE and the extinction coefficient $(k)$, and between PAR and HI in the Canterbury environment. The present study showed that variation in RUE was inversely related to differences in $k$. This is to be expected, as canopies with erect leaves will spend less time with highly light saturated leaves than a canopy of flat leaves. Stützel \& Aufhammer (1992), in $V i c i a$ faba, also found that $k$ decreased with increased GAI. Data from the present study on four grain legumes sown at different plant populations with both mechanical and hand sowing confirm this.

The relationship of TDM and seed yield, at final harvest, with total intercepted PAR was strong (Fig. 8). The slope of the TDM and total intercepted PAR regression indicate comparatively high RUE values in both seasons in all four legume species. These values are higher than the mean RUE values (Tables 3 and 4) because the lines did not pass through the origin (Fig. $8 a, b$ ). This is identical with results from lentil (McKenzie \& Hill 1991) and pea (Zain et al. 1983). However, in the RUE 1999/2000 was lower. The lower minimum temperatures in 1999/2000 (Fig. 1) may have contributed to the lower RUE values than in 1998/99. Gardner \& Auma (1989) and Bell et al. (1993) in peanut and Andrade et al. (1993) in maize all reported that RUE was sensitive to low minimum temperatures.

Seed yield was linearly related to total intercepted PAR $\left(R^{2}=0.77\right.$ to 0.98$)$ and the slopes show that from 0.90 to $1.50 \mathrm{~g} \mathrm{seed} / \mathrm{m}^{2}$ was produced from each MJ of absorbed PAR in the different legume species. The highest yielding species had the highest final RUE. This was closely related to TDM, seed yield and $\mathrm{HI}$, but was inversely related to $k$ in all four 

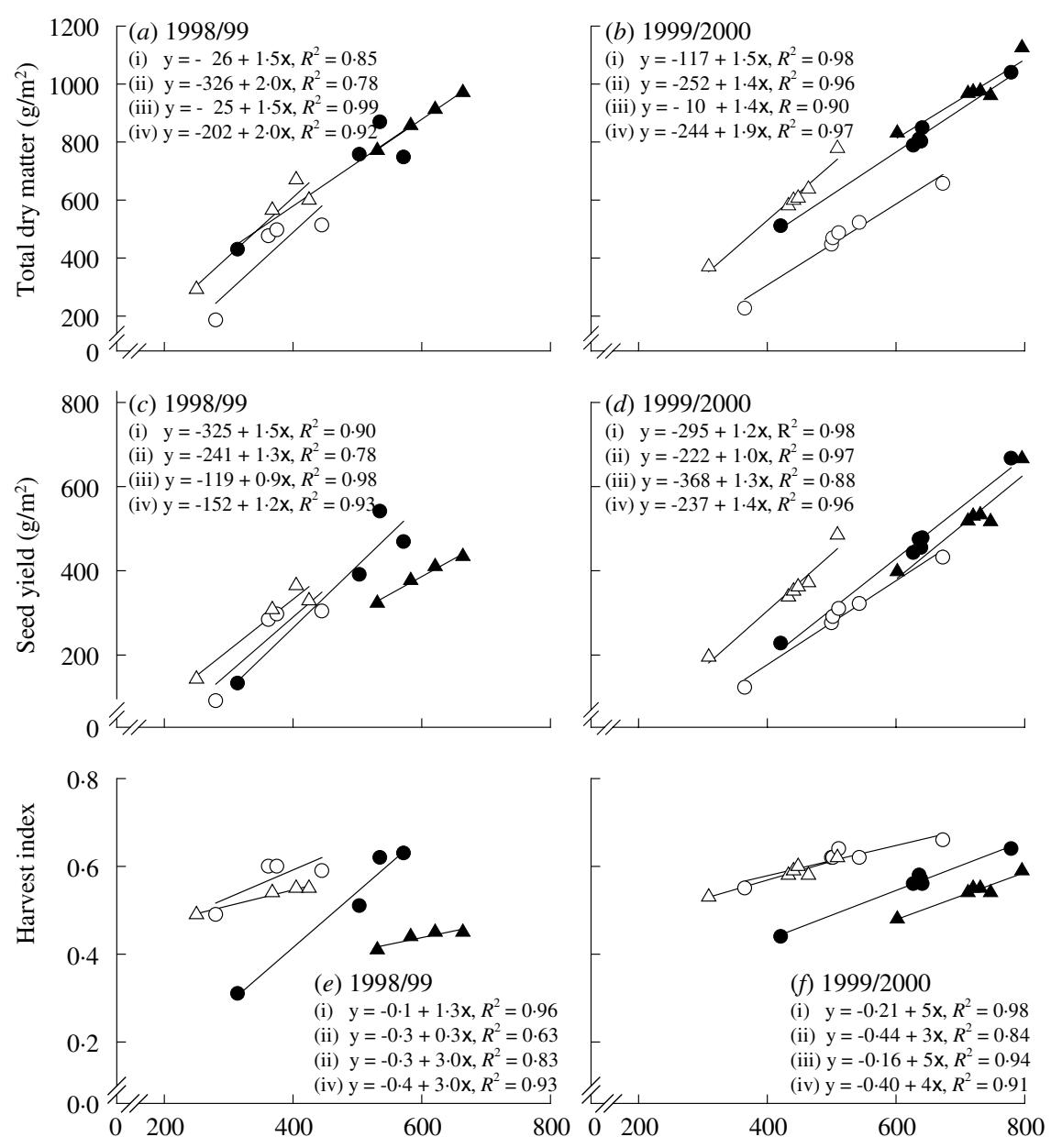

Total season intercepted PAR $\left(\mathrm{MJ} / \mathrm{m}^{2}\right)$

Fig. 8. The relationships of total seasonal intercepted photosynthetically active radiation (PAR) with total DM production, seed yield and crop HI of four grain legumes at final harvest in 1998/99 and 1999/2000. Chickpea (eqn i, O) lentil (eqn ii, O), narrow-leafed lupin (eqn iii, $\mathbf{\Delta}$ ), pea (eqn iv, $\triangle$ ).

species in the present study. These variations might affect HI. As RUE is a key determinant of crop yield, HI can be stabilized by stabilizing the RUE.

The results show that higher plant populations gave increased GAIs when compared with the lower plant population in all four legumes. Total dry matter, seed yield and crop HI were strongly correlated with total seasonal intercepted PAR. The RUE was directly related to TDM production, seed yield and CHI. The RUE increased with increased plant population up to $2 \cdot 0 \times$ optimum in the first trial and up to 400 plants $/ \mathrm{m}^{2}$ in the second experiment. It was stable over different sowing depths. The differences in RUE were inversely related to differences in the extinction coefficient. The results also suggest that in a subhumid temperate environment such as Canterbury, grain legumes should primarily be selected for the development of a large GAI, which will maximize interception of PAR, DM production and consequently crop seed yield.

\section{REFERENCES}

Andrade, F. H., Uhart, S. A. \& Cirilo, A. (1993). Temperature affects radiation use efficiency in maize. Field Crops Research 32, 17-25.
Anwar, M. R. (2001). Water use of Kabuli chickpea (Cicer arietinum L.) cultivars in Canterbury. Ph.D. Thesis, Lincoln University, Canterbury. 
Ashraf, K., Akbar, M. \& Salim, M. (1994). Genetic improvement in physiological traits of rice yield. In Genetic Improvement of Field Crops (Ed. G. A. Slafer), pp. 413-455. New York: Marcel Dekker.

Ayaz, S., McKenzie, B. A. \& HiLl, G. D. (1999). The effect of plant population on dry matter accumulation, yield and yield components of four grain legumes. Agronomy New Zealand 29, 9-15.

Ayaz, S., McNeil, D. L., McKenzie, B. A. \& Hill, G. D. (2001). Population and sowing depth effects on yield components of grain legumes. Proceedings of the Australian Agronomy Conference 10, 342-346.

Ayaz, S., McKenzie, B. A., Hill, G. D., McNeil, D. L. (2004). Variability in yield of four grain legume species in a subhumid temperate environment I. Yields and harvest index. Journal of Agricultural Science, Cambridge 142, 9-19.

Bell, M. J., Wright, G. C. \& Harch, G. R. (1993). Environmental and agronomic effects on growth of four peanut cultivars in a sub-tropical environment. I. Dry matter accumulation and radiation-use efficiency. Experimental Agriculture 29, 473-490.

Birch, C. J., Hammer, G. L. \& Rickert, K. G. (1998). Improved methods for predicting individual leaf area and leaf senescence in maize (Zea mays). Australian Journal of Agricultural Research 49, 249-262.

Fasheun, A. \& Dennett, M. D. (1982). Interception of radiation and growth efficiency in field beans (Vicia faba L.). Agricultural Meteorology 26, 221-229.

Gallagher, J. N. \& Biscoe, P. V. (1978). Radiation absorption, growth and yield of cereals. Journal of Agricultural Science, Cambridge 91, 47-60.

Gardner, F. P. \& Auma, E. O. (1989). Canopy structure, light interception, and yield and market quality of peanut genotypes as influenced by planting pattern and planting date. Field Crops Research 20, 13-29.

Haloi, B. \& Baldev, B. (1986). Effect of irrigation on growth attributes in chickpea when grown under different dates of sowing and population pressure. Indian Journal of Plant Physiology 29, 14-27.

HaY, R. K. M. \& Walker, A. J. (1989). An Introduction to the Physiology of Crop Yield. Harlow, UK: Longman Scientific and Technical.

Herbert, S. J. (1977). Density and irrigation studies in Lupinus albus and Lupinus angustifolius. Ph.D. Thesis. Lincoln College, University of Canterbury.

Hewitt, A. E. (1992). New Zealand soil classification. DSIR Land Resources Scientific Report No. 19.

Hipps, L. E., Asrar, G. \& Kanemasu, E. T. (1983). Assessing the interception of photosynthetically active radiation in winter wheat. Agricultural Meteorology 28, 253-259.

Hughes, G., Keatinge, J. D. H., Cooper, P. J. M. \& Dee, N. F. (1987). Solar radiation interception and utilization by chickpea (Cicer arietinum L.) crops in Northern Syria. Journal of Agricultural Science, Cambridge 108, 419-424.

Husain, M. M., Hill, G. D. \& Gallagher, J. N. (1988). The response of field beans (Vicia faba) to irrigation and sowing date. 2. Growth and development in relation to yield. Journal of Agricultural Science, Cambridge 111, 233-254.

Kiniry, J. R., Jones, C. A., O' Toole, J. C., Blanchet, R., Cabelguenne, M. \& Spanel, D. A. (1989). Radiation-use efficiency in biomass accumulation prior to grain-filling for five grain-crop species. Field Crops Research 20, $51-64$.
Knott, C. M. (1987). A key for stages of development of the pea (Pisum sativum). Annals of Applied Biology 111, 233-245.

Loss, S. P., Siddique, K. H. M., Jettner, R. \& Martin, L. D. (1998a). Response of faba bean to sowing rate in south-western Australia. I. Seed yield and economic optimum plant population. Australian Journal of Agricultural Research 49, 989-997.

Loss, S. P., Siddique, K. H. M., Martin, L. D. \& Crombie, A. $(1998 b)$. Response of faba bean (Vicia faba) to sowing brate in south-western Australia. II. Canopy development, radiation absorption and dry matter partitioning. Australian Journal of Agricultural Research 49, 999-1008.

Martín, I., Tenorio, J. L. \& Ayerbe, L. (1994). Yield, growth, and water use of conventional and semi-leafless peas in semiarid environments. Crop Science 34, $1576-1583$.

McKenzie, B. A. \& Hill, G. D. (1991). Intercepted radiation and yield of lentils (Lens culinaris Medik.) in Canterbury New Zealand. Journal of Agricultural Science, Cambridge 117, 339-346.

Monteith, J. L. (1965). Light distribution and photosynthesis in field crops. Annals of Botany 29, 17-37.

Pilbeam, C. J., Hebblethwaite, P. D., Nyongesa, T. E. \& Ricketts, H. E. (1991). Effects of plant population density on determinate and indeterminate forms of winter field beans (Vicia faba). 2. Growth and development. Journal of Agricultural Science, Cambridge 116, 385-393.

Schulz, S., Keatinge, J. D. H. \& Wells, G. J. (1999). Productivity and residual effects of legumes in rice-based cropping systems in a warm-temperate environment. I. Legume biomass production and $\mathrm{N}$ fixation. Field Crops Research 61, 23-35.

Silim, S. N. \& Saxena, M. C. (1992). Comparative performance of some faba bean (Faba bean L.) cultivars of contrasting plant types. 2. Growth and development in relation to yield. Journal of Agricultural Science, Cambridge 118, 333-342.

Silim, S. N., Saxena, M. C. \& Erskine, W. (1993). Adaptation of lentil to the Mediterranean environment. I. Factors affecting yield under drought conditions. Experimental Agriculture 29, 9-19.

Sinclair, T. R. \& Muchow, R. C. (1999). Radiation use efficiency. Advances in Agronomy 65, 215-265.

SingH, K. B. (1997). Chickpea (Cicer arietinum L.). Field Crops Research 53, 161-170.

SingH, P. (1991). Influence of water deficits on phenology, growth and dry matter allocation in chickpea (Cicer arietinum). Field Crops Research 28, 1-15.

Stützel, H. \& Aufhammer, W. (1992). Grain yield in determinate and indeterminate cultivars of Vicia faba with different plant distribution patterns and population densities. Journal of Agricultural Science, Cambridge 118, 343-352.

Szeicz, F. (1974). Solar radiation in crop canopies. Journal of Applied Ecology 11, 1117-1156.

Thomas \& FukAI, S. (1995). Growth and yield response of barley and chickpea to water stress under three environments in southeast Queensland. I. Light interception, crop growth and grain yield. Australian Journal of Agricultural Research 46, 17-33.

Thomson, B. D. \& Siddique, K. H. M. (1997). Grain legume species in low rainfall Mediterranean-type environments. 
II. Canopy development, radiation-use efficiency and dry matter production. Field Crops Research 54, 189-199.

Trapani, N., Hall, A. J., Sadras, V. O. \& Vilella, F. (1992). Ontogenetic changes in radiation use efficiency of sunflower (Helianthus annuus L.) crops. Field Crops Research 29, 301-316.

Verghis, T. I. (1996). Yield and yield development of chickpea (Cicer arietinum L.). Ph.D. Thesis, Lincoln University, Canterbury.
Wilson, C. E. \& Thurling, N. (1996). Effect of sowing depth and water potential on seedling emergence of Lupinus species. Australian Journal Experimental Agriculture 36, 463-471.

Zain, Z. M., Gallagher, J. N., White, J. G. H. \& Reid, J. B. (1983). The effect of irrigation on radiation absorption, water use and yield of conventional and semileafless peas. Proceedings of the Agronomy Society of New Zealand 13, 95-102. 